\title{
Organisational culture at a South African food service company
}

\author{
A. Thomas* and D. Lindsay \\ Graduate School of Business Administration, \\ University of the Witwatersrand, PO Box 98, \\ Wits 2050, Republic of South Africa \\ thomas.a@wbs.wits.ac.za or adelet@megaweb.co.za
}

\section{Received October 2003}

\begin{abstract}
The aim of the present exploratory study was to examine whether congruence exists between the organisational culture perceived to be evident at Compass, South Africa and the strategic objectives of the company. Information from the administration of the Harrison and Stokes (1992) instrument to measure existing and preferred organisational culture orientations was obtained from a sample of 86 employees representing two employee groupings at the company. The findings indicate that a difference in perception of the existing culture is evident between the CEO and the two employee groups and that there is a lack of alignment of the culture with the strategic objective of the company. The findings further suggest that there is consensus among the employee groups about the preferred culture that would appear to support the company strategy. Recommendations with regard to developing an organisational culture to support company strategic intent relate to the development of a learning organisation and the role of leadership in driving culture change.
\end{abstract}

*To whom all correspondence should be addressed.

\section{Introduction}

The Compass Group, South Africa (Compass) is the southern African division of the multinational food service and hospitality organisation, Compass plc. The local operation has been the leader in South Africa in the contract food service market and in the retail and remote-site food service sectors. Compass, South Africa has experienced exceptional growth from its inception in 1985, with turnover increasing from R50 million at that time to R700 million in 2000 (Compass South Africa, 2001).

The main success factor at Compass is perceived to be the ability of the company to change its image. Schaefer (2001:4) notes that Compass 'has 'changed' its appearance over the years to maintain its position as a leading contract food service provider to the South African market .... This growth and development can be largely attributed to the many successful decisions made by management in steering the company through the highly competitive contract food service market'. Effective use of strategy was apparent in the history of Compass and this skill combined with vision on the part of the leaders, has resulted in the growth of the company and its domination of the market in a highly competitive environment.

At the time of undertaking the present research (2001), the contract food service industry world-wide was undergoing a metamorphosis whereby the traditional low-margin service concept that had come to be recognised as 'canteen fare' was being replaced by a higher margin retail standard. This shift had not only the capacity to reduce catering subsidies for the client but also presented customers with a more attractive dining experience and improved contract retention and profit margins for the caterer. Through the Compass plc connection, Compass South Africa was able to gain immediate access to the technology and expertise required to introduce these concepts locally, a move which management saw as being pivotal in their strategy to make Compass South Africa the leading food service company, within chosen market segments, in the Southern African Development Community (Compass, South Africa, 2001). The idea of being a 'learning organisation' was seen as a means of achieving this strategic intent. (Compass, South Africa, 2001).

In 2001, the CEO noted resistance to the introduction of this new generation food service concept. The sales team was succeeding in selling the product to new clients but operations personnel cited client resistance and operational considerations as reasons for the lack of transformation of existing contracts. The overall purpose of the present study, therefore, was to examine whether congruence exists between the organisational culture perceived to be evident at Compass and the strategic objective of the company to introduce new food service concepts to ensure its position as the market leader in the industry.

\section{Literature review}

Brown (1995) notes that the study of organisational culture evolved from the work on organisational climate conducted 
in the 1970s where beliefs and attitudes held by employees of their organisations were studied. Early attempts to define the broader concept of 'culture' upon which the concept of 'organisational culture' is based, are associated with the development of the academic disciplines of sociology and anthropology (Jenks, 1993). Broadly, the concept 'culture' represents 'an interdependent set of values and ways of behaving that are common in a community and that tend to perpetuate themselves, sometimes over long periods of time' (Kotter \& Heskett, 1992:141). The definitions of organisational culture that have been advanced in the literature over the years (Jacques, 1952; Pettigrew, 1979; Siehl \& Martin, 1984; Ohmae, 1989; Schein, 1992; 1996) generally refer to shared understandings or patterns of meaning between groups of people in an organisation (Hatch, 1997). Hofstede (1997:180) defines organisational culture as 'the collective programming of the mind which distinguishes the members of one organisation from another' while Schein's (1992:12) definition of culture, and by extension, organisational culture, is one of 'a pattern of shared basic assumptions that the group learned as it solved its problems of external adaptation and internal integration, that has worked well enough to be considered valid and, therefore, to be taught to new members as the correct way to perceive, think and feel in relation to those problems'. Harrison and Stokes (1992:1) define organisational culture as 'the pattern of beliefs, values, rituals, myths and sentiments shared by members of an organization ... which influences the behavior of all individuals and groups within the organization'.

\section{Perspectives on organisational culture theory}

Organisational culture research is concerned with the perceptions employees have of the organisation, not with whether or not they agree with such perceptions (Robbins, 1998). However, these perceptions could influence their work patterns (Struwig \& Smith, 2002). In order to understand how groups of people are likely to respond in different environments and to different situations, tools have been developed to measure cultural values (Rokeach, 1973; Harrison \& Stokes, 1992; Trompenaars, 1993).

Schein's (1992) three-level model of organisational culture is useful for an understanding of cultural processes within organisations. At the deepest level, the basic assumptions of employees represent what they believe to be acceptable and true. These assumptions are deeply rooted and employees do not consciously consider them, nor can they easily identify or talk about them. They are issues that are taken for granted and acted upon. While individual employees bring basic assumptions of their own with them when they join a company, as group members in the workplace, they also develop others that are unique to that workplace. Basic assumptions can be changed but this is a slow and difficult process (Schein, 1992).

At the next level, the values of the organisation, incorporating norms of behaviour represent those issues that employees consciously care about. Norms are the agreed standards and patterns of behaviour and are supported by the values of the organisation. Values are also invisible and are manifested in the behaviour of employees. The concept of 'organisational values' generally refers to the values of the leaders of the organisation (Hofstede, 1997). These values of the leaders can differ from those of employees but both would be almost impossible to change making it therefore important for the maintenance of culture that employees recruited share the values of the leaders (Hofstede, 1997).

According to Schein (1992), at the third level, artefacts are the most visible aspects of the culture of an organisation. They are easily observable but difficult to decipher as the rationale for the value attached to artefacts is based at the lower levels of culture.

When changes occur in an organisation, the impact may be seen at the artefact level but the response would depend on the impact of the change on the values, norms and basic assumptions of the stakeholders affected by the changes and only by scrutinising values, norms and artefacts can basic assumptions be identified (Schein, 1992).

Harrison and Stokes (1992) assert that the culture of every organisation is made up of a combination of four distinct cultural orientations: power, role, achievement and support. Each of the four cultural orientations, typically, would involve a distinct management style that would evoke a characteristic response from employees. While none of the four orientations is right or wrong, some would be more appropriate for particular work environments than others.

\section{Power}

The power-oriented culture indicates unequal access to resources. Employees have come to accept that direction and control are vested in the leader and that a clear hierarchy of command exists. In such a culture, there would be little empowerment of employees and all direction would emanate from the top. Employees have realised that initiative is not welcomed and have learned to expect direction. In order to operate a business successfully in this kind of environment, a high degree of order and structure is required which increases as the organisation grows. Power cultures are the norm in Latin American and many Asian societies but may not be suited to the current environment in South Africa (Thomas \& Bendixen, 2000).

Motivating factors in power-oriented cultures are extrinsic, comprising rewards and punishment, coupled with a desire to be associated with a strong leader. A major long-term consideration for companies that adopt this culture would be that it can result in a lack of internally developed managerial talent. This shortage can occur due to the fact that in the process of development, employees have not been encouraged to develop initiative and creativity and have become accustomed to being dependent. New managers, therefore, often have to be attracted from outside the organisation (Harrison \& Stokes, 1992).

\section{Role}

The role-oriented culture develops out of a need for structure and regulation in the working environment. While this might be wholly appropriate to some situations, it could impede the development of others. For example, some 
employees of an airline need to adhere strictly to agreed procedures to ensure safety, accurate scheduling and efficient use of assets. Others meanwhile, must be empowered to manage within a set of guidelines rather than strict rules so as to be able to satisfy diverse customer needs. Harrison and Stokes (1992) note that a role culture will generally develop wherever a power-oriented culture is dominant and that extrinsic rewards are required to motivate employees in such an environment. The role culture is not generally indicated with a high achievement or support oriented culture.

\section{Achievement}

An achievement-oriented culture is one in which employees are internally motivated. To be internally motivated, employees need to feel valued and appreciated for their personal contribution and potential. They need the freedom to interpret situations and apply what they believe to be the correct solution. Well-selected, well trained and empowered employees who operate in an environment of trust and support, therefore, are essential ingredients for the creation and maintenance of such a culture. Although an achievement culture is contra-indicated by a power culture, some elements of the power culture are needed to drive the organisation. These include acceptance of the leader and of his/her proposals. Strong leadership is critical to an achievement culture, but the type of leadership needed guides, excites and rallies employees behind a common purpose rather than dictating the purpose and then binding employees to it.

Where the achievement culture is dominant, Harrison and Stokes (1992) note, there would usually be elements of a role orientation, especially as the organisation grows. This occurs both because humans need some form of structure in their lives and because no large organisation can function efficiently without it.

\section{Support}

In the support orientation culture, truth, love and commitment to fellow employees as well as to the organisational entity are valued. In support-oriented organisations it is assumed that people want to contribute out of commitment to their colleagues and to the organisation, due to their sense of belonging. This culture is important to the effective development of an achievement culture. Without a balance of caring, that is inherent in the support culture, the achievement culture can lead to unbridled competition between employees and to a lack of appreciation of the benefits of collective, as opposed to individual, effort (Harrison \& Stokes, 1992).

\section{Managing organisational culture}

A body of opinion exists regarding a perceived need to include, within organisational cultures in South Africa, the varying cultural values of the diverse groups that make up the employee population (Christie, Lessem \& Mbigi, 1993; Boon, 1997; Thomas \& Turpin, 2002). However, Thomas and Bendixen (2000) found that South African middle managers shared similar cultural values regardless of ethnic background. This study found that these results aligned the South African middle managerial culture closely with aspects of western countries such as the USA, Great Britain, and Holland. When compared with the results of a previous study completed by Hofstede in 1980, these results indicated that a shift had occurred in the culture of the management environment in South Africa manifested in a lower tolerance of hierarchy in the workplace and a greater focus on equality.

The lengthy process of changing the fundamental cultural orientation requires changes in value systems and management styles and also can affect organisational structures and operating and reward systems (Handy, 1985). In this vein, Young (2000) notes that any attempt to manage or change organisational culture requires attention to be paid to systems and processes of motivation, conflict management, management control, customer/client management, strategy formulation, and authority and influence.

The link between culture and economic performance has been discussed in the literature (Ulrich \& Lake, 1991; Van der Post, De Coning \& Smit, 1998; Deal and Kennedy, 1999; Connors \& Smith, 2000). Cummings \& Worley (2001) note that organisational culture that is well-conceived and well-managed and one that is closely linked to an effective business strategy can often mean the difference between success and failure in a demanding and changing environment. This principle was borne out earlier by Kotter and Heskett (1992). Schwab (1999) asserts that corporate cultures can be unhealthy and stifle productivity, thereby inhibiting creativity and dynamism. Similarly, Markides (1999) maintains that in order to be successful, the management of a company needs constantly to be prepared to change and should create a culture that welcomes change even if it disrupts the status quo.

\section{Leadership and organisational culture}

An employee who joins an organisation brings with him/her values and beliefs that govern attitudes, behaviour and identity (Hatch, 1997). Where this person is the leader, these beliefs, values and assumptions become the main influence on the culture of the organisation (Blanchard \& O'Connor, 1997; Hofstede, 1997; Ogbonna \& Harris, 2000). As strategic direction generally emanates from the leader, it will inevitably be affected by his/her personal culture orientation that becomes absorbed into the broader organisation. Eventually these strategic norms become embedded at the level of basic assumptions to which employees unconsciously adhere and so the culture becomes selfperpetuating (Schein, 1992).

In companies that have managed to adapt successfully to changing environments, Hatch (1997) notes that the leaders have often initiated incremental changes in both strategies and practices and that these changes have tended to address the needs of all stakeholder groups equitably (Kotter \& Heskett, 1992). Beer and Nohria (2000) believe that for successful change to occur, leaders must balance the focus on improving value to the shareholder with that of developing the organisational capability (that would include 
the addressing of organisational culture). They assert that an over-emphasis on the former could result in short-lived benefits, as organisational inertia would eventually counteract the gains. On the other hand, an over-emphasis on organisational capability could undermine the achievement of the economic objective, as the process would lose momentum and become immersed in processes and procedures.

Schein (1992) highlights the importance of recognising within organisations that the basic assumptions held by influential members could be flawed and might need to be challenged. Not only do these basic assumptions govern the behaviour of employees but there is also a risk that the leaders themselves could make decisions in accord with their assumptions, rather than with reality. Schein (1992:5) posits that 'one of the most decisive functions of leadership is the creation, management, and sometimes even the destruction of culture'. Harrison and Stokes (1992) suggest that this danger is particularly inherent in high power cultures where senior managers can be isolated from valuable feedback as employees are reluctant to take an unpopular stance or to challenge the authority of the leader.

\section{Methodology}

\section{Sample}

The sample comprised 476 employees (from supervisor level upwards) of the Compass Group, South Africa. These employees are regarded as ones who broadly can be considered to be decision-makers within the company. These employees were surveyed using the Harrison and Stokes (1992) instrument. This sample was categorised into two groups viz. the 20 executives on the Mirror Board (the committee charged with the daily management of the company) and the 455 operations/administrative staff. The CEO of Compass was included in the study as a separate entity, the rationale being that the CEO, as leader, exerts a strong influence on the culture of the organisation and his response was therefore required as an indication of the direction in which the culture would be likely to move (Ogbonna \& Harris, 2000). The line management employees on the Mirror Board could be expected to interpret this cultural input and transfer it to the employees (Kotter \& Heskett, 1992). Accordingly, it was deemed important to establish the level of commonality between their responses and those of the CEO and operations/administrative employees who could be expected to be involved in the daily implementation of the strategies of the company.

\section{Data collection and analysis}

Responses were obtained from 143 employees, with 86 usable responses (18 percent of the sample). The breakdown of members within this sample was as follows: $\mathrm{CEO}=1$; Mirror Board members $=10$; operations/administrative staff $=75$.

The Harrison and Stokes (1992) instrument aims to measure both the existing culture and the preferred culture as perceived by members of an organisation. Perceptions of preferred and existing culture are both measured on a four- point scale (from the dominant view or most preferred alternative $=4$, to the least dominant view or least preferred alternative $=1$ ) that relates to four culture orientations (power, role, achievement, support). Ashkenasy, Broadfoot and Falkus (2000), in their assessment of 18 questionnaire measures of organisational culture, classify the Harrison and Stokes (1992) instrument as a 'typing' tool, suited to describing, rather than profiling the culture of an organisation. The same authors note the suitability of such instruments to the measurement of culture change over time. A major consideration in the selection of the instrument was its brevity and simplicity of completion. The instrument is described as having moderately good reliability on all dimensions other than the role dimension and evidence of construct validity comes from research conducted by the authors of the instrument (Harrison \& Stokes, 1993).

The results were analysed using the scoring system pertaining to the instrument (Harrison \& Stokes, 1992) where each of the possible question endings or phrases in the instrument represents one of the four dimensions power, role, achievement and support. As described earlier, respondents are asked to allocate a $1,2,3$ or 4 to the phrases, according to the relevance of the ending to the situation being described. Each of these four numbers may only be allocated once i.e. the total score to every question must add up to 10 . By adding all the responses to a specific question, therefore, and dividing by the number of respondents, the average perspective is arrived at. The noting of the actual allocation of $1,2,3$, and 4 scores provides information about the dominant view.

The analysis culminated in an overall picture along the four culture dimensions for the sample as a whole as well as separate analyses pertaining to the CEO, the Mirror Board members and the operations/administrative staff as distinct groupings. The results were interpreted using the profiles that accompany the instrument (as discussed in the literature review) and in accordance with literature on the subject.

The results of the research were expected to inform the following questions:

1. What are the perceptions of company culture from the perspectives of the CEO, the Mirror Board members and operations/administrative employees?

2. Is there agreement amongst members of the sample with regard to perceptions of organisational culture?

3. Are the perceptions of existing culture, held by sample members, in conflict with the strategic objective of the company?

\section{Limitations of the study}

1. The confidential nature of the survey process precluded obtaining other demographic details from respondents apart from the two broad categories of employment and there was no way of knowing whether responses were biased in favour of one or more groups of employees based on any other demographic factors; 
2. It is possible that there may have been a greater response rate from employees who felt strongly about issues pertaining to organisational culture, thereby resulting in bias and impacting on the generalisation of the findings to the entire company;

3. The Harrison and Stokes (1992) instrument was available only in English. This might have presented difficulties to some employees for whom English was not a first language and may have affected the response rate and/or interpretation of the questions;

4. The small sample size has implications for the generalising of findings, and accordingly the present study should be viewed as an exploratory one that lays groundwork for future research in the area.

\section{Results}

The response of the sample suggests that employees perceived the company culture as being high power/role oriented, as shown in Figure 1. In such a situation, the assumption would be that employees should defer to those in positions of authority and await instruction, as opposed to being pro-active (Harrison \& Stokes, 1992). One would also expect to find a strong orientation around the application of policy and procedure in decision-making and problemsolving situations as opposed to subjective analysis of individual situations.

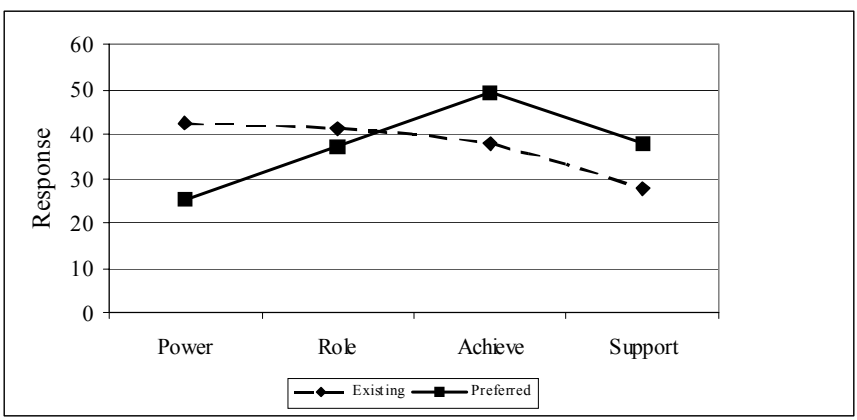

Figure 1: Average response: Sample

However, Figure 1 represents a global view, being based on an average of all the responses of the sample. As such, it conceals the possible existence of sub-groups and modal variations within the overall results, the modal variations providing information about the dominant view within the group.

In order to aid an understanding of the influences on, and the direction of the culture, the analysis was broken down for the CEO, Mirror Board members and operations/administrative employees. Figure 2 indicates the differences of existing and preferred culture for each of these three groups.

Figure 3 demonstrates the dominant view held by employees generally and Figures $4 \& 5$, the dominant view in the Mirror-Board and operations/administrative groups respectively.

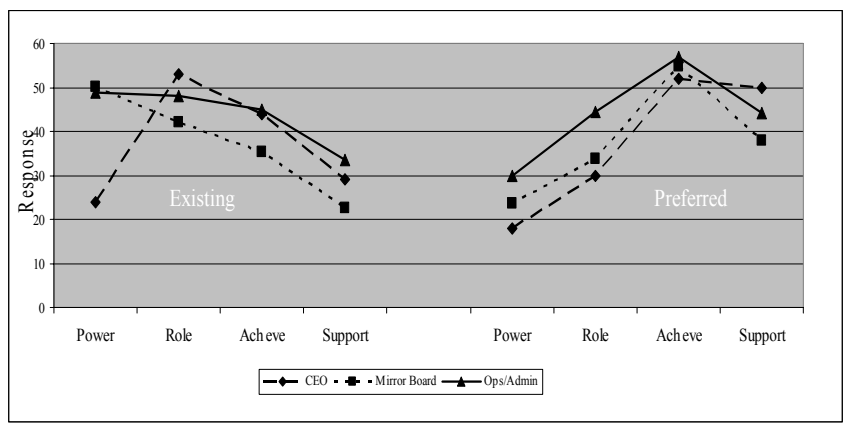

Figure 2: Average response: employee grouping

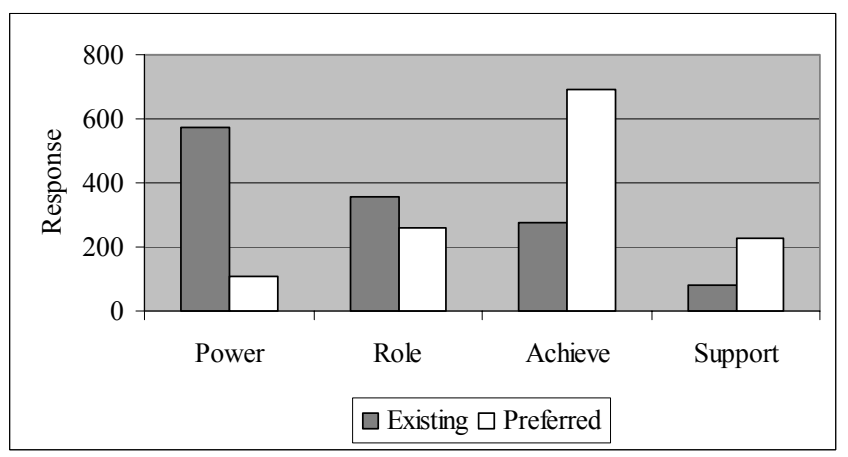

Figure 3: Cumulative frequencies: Dominant view Sample $(n=86)$

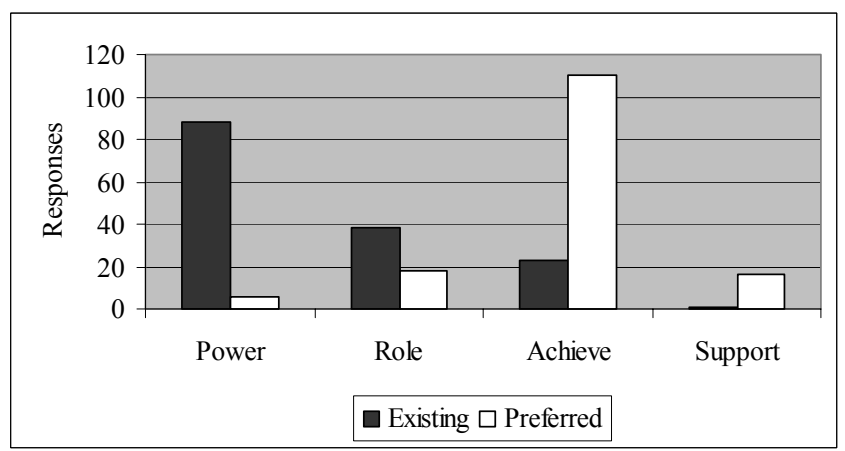

Figure 4: Cumulative frequencies: Dominant view Mirror Board $(\mathbf{n}=\mathbf{1 0})$

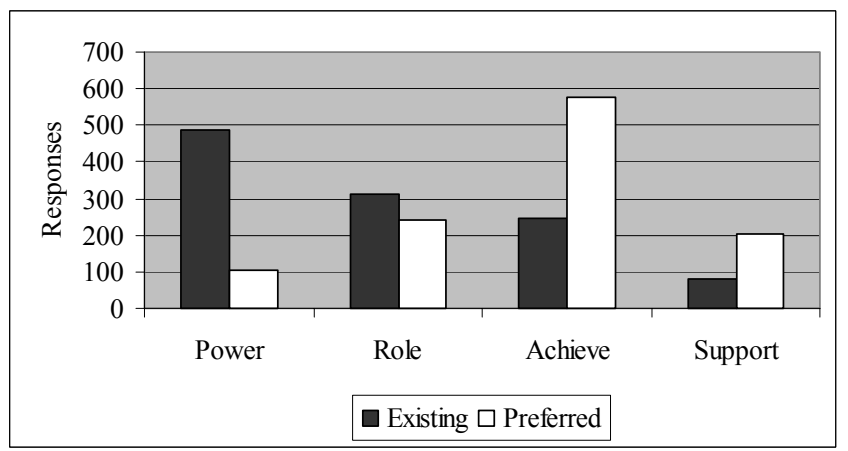

Figure 5: Cumulative frequencies: Dominant view

Operations/administrative employees $(n=75)$

\section{Discussion}

\section{Existing culture}

Sample members generally perceived a power orientation to exist within the company with little support. The pattern of 
responses with regard to the existing culture would seem to suggest that the CEO has a different perspective of the company culture from that held by the Mirror Board and administrative/operations group members (see Figure 2). In this regard, three specific points are noteworthy:

1. From Figure 2 it is indicated that the CEO appears to perceive a 'democratic' culture, characterised by a low power orientation but, paradoxically, one that is high in structure (role). He appears to perceive a reasonable level of empowerment and initiative at work (as indicated by role and achievement) but a lack of commitment and support from employees toward one another and towards the organisation;

2. The Mirror Board members seem to perceive a more extreme culture whereby power is used to manage the organisation (see Figure 2). They perceive little camaraderie (support) or opportunity to show initiative (achievement) and see the operating environment as highly structured and rule-driven (power);

3. While the average view of the operations/ administrative employees suggests that they perceive power, role and achievement orientations to be of almost equal influence (Figure 2), the distribution of scores suggests differently in that the organisation is believed to be predominantly power-driven (see Figure $5)$.

Harrison and Stokes (1992) note that top managers in highpower organisations can be isolated from feedback due to the nature of their management style and the reluctance of employees to challenge them. Although the majority of the Mirror Board members were drawn from the ranks of the operations/administrative group, their cultural orientation is now distinctly more orientated toward the power and role dimensions. Schein (1996) has noted that it is the culture of the 'operators' or front-line employee group that underpins the cultural identity of the organisation at any point in time. However, he also notes that the leadership has a strong influence on the culture of the organisation and that this leadership orientation will eventually filter through to all employees of the company thus eventually altering the overall cultural profile (Schein, 1996). It is suggested that this new cultural influence, experienced by appointees to the Mirror Board, emanates from the CEO who may be promoting the development of a power-role cultural orientation. New Mirror Board members, upon leaving the relatively democratic and participative environment of the operations/administrative grouping, enter an area where they soon come to see the company as being controlled from the top and bureaucratically oriented (power). They perceive little scope for the use of initiative or creativity (achievement) and they also perceive a low level of empathy amongst other employees (support). Schein (1996) would suggest that this influence will eventually flow down through the entire organisation eventually altering the cultural profile of the operations/administrative employees to match that of the Mirror Board and CEO. Such a situation, it is suggested, would be undesirable as the resultant cultural profile would not be indicated for success in a competitive, service-related environment (Kotter \& Heskett, 1992).

\section{The preferred culture}

The findings indicate that there is consensus about the preferred culture viz. one of a high achievement/support orientation with lower power/role influences (see Figure 2). Preference for this profile is widely indicated in western societies (Hofstede, 1997) and is presented as a united point of reference towards which everyone could work. However, the existing cultural perspective may influence the views of members of the Mirror Board and operations/administration groups with regard to the extent to which people believe that change could be effected contrary to the more optimistic view of the CEO (see Figure 2) that a move from the existing to the preferred culture is possible.

From Figure 2 it can be seen that a gap exists between the perceptions of the CEO and those of the other two groups that are more closely aligned in terms of perceptions of existing and preferred cultures. However, all parties perceive a noticeable difference between the existing and preferred cultural orientations that indicates a need for action on the issue.

From the above, the following conclusions can be drawn:

1. There is general dissatisfaction with the current culture of the company, which could be a cause of the resistance to change as perceived by the $\mathrm{CEO}$;

2. The perception of the existing culture held by the CEO is not shared by the sample members;

3. The existing organisational culture orientation of power/role, it is suggested, would not support the sentiments of a learning organisation as a tool to be used in the achievement of the company strategy of introducing cutting-edge food service concepts to ensure market leadership. In this regard, the culture and the future direction in which it is advancing, appear not to be aligned to the stated strategy of the organisation;

4. The preferred cultural orientation (high achievement/support) noted by sample members would support the sentiments of a learning organisation (Senge, 1990) as a tool to be used in achieving strategic intent;

5. The existing culture may impact negatively on the performance of the company as it is in conflict with the strategic objective of the company (Kotter \& Heskett, 1992).

In South Africa, it has been noted that middle management employees of all races are averse to a high power orientation in the work environment (Thomas \& Bendixen, 2000). Similarly, the accepted philosophy in the service industry sector in the western world appears to be that the most productive workforce is one that is empowered and that operates within a flexible environment (Hofstede, 1997; 
Kotter \& Heskett, 1992). Accordingly, the most appropriate cultural orientation for Compass, it is suggested, is one of a high achievement/support orientation.

\section{Recommendations and conclusion}

Compass has, as its strategic intent, the development of innovative leading-edge food service solutions. For employees to embrace such change, it is suggested that an inclusive, empowered culture would need to be developed away from the perceived dominant power/role orientation. Accordingly, the following recommendations are furnished to the management of the company.

The dissatisfaction expressed by members of the sample with the existing power/role culture could be deemed to be positive in that such dissatisfaction could be a catalyst to change a culture that does not encourage experimentation with new ideas and concepts. The management of Compass and the CEO, in particular, should capitalise upon such dissatisfaction as Kotter (1995) notes that dissatisfaction with the status quo and the creation of a sense of urgency for change are essential ingredients for any change process. In order to develop a culture of learning, top leadership in the company must drive this process, including the development of an inclusive and shared vision, the appointment of a change management team to drive the process with the CEO, the creation of opportunities for success and the strengthening of communication throughout the organisation around the desired vision and strategic intent (Nadler \& Tushman, 1990; Ulrich \& Lake, 1991; Kotter \& Heskett, 1992; Kotter, 1995; Beer \& Eisenstat, 2000; Beer \& Nohria, 2000).

The learning organisation concept needs to permeate the entire organisation. It requires a shift away from traditional power-oriented management practice, coupled with a longterm commitment to the empowerment of employees within a predominantly achievement/support cultural orientation.

The underlying concept is that in such a supportive environment, employees would not be afraid to explore and experiment and that in so doing they would willingly share their latent knowledge to the benefit of the organisation. Because a power-oriented culture does not nurture initiative and debate, working together for the achievement of the stated strategic objective of Compass will inevitably be a biased process until the culture is changed.

In this regard, Garvin (1993) notes that the steps involved in the creation of a learning organisation include:

- $\quad$ the fostering of an environment conducive to learning by creating time and space within the operation for management and employees to reflect on and analyse company strategies and the current working environment;

- the removal of boundaries within the organisation that would otherwise insulate groups of people, reinforce preconceptions and limit the sharing of ideas; and
- the facilitation of learning forums in which the processes, policies, procedures and expected outcomes could be examined by employees through the application of new knowledge gained from both external and internal sources.

In conclusion, Welch (2000:4) notes that 'a company can boost productivity by restructuring, removing bureaucracy and downsizing, but it cannot sustain high productivity without cultural change'. The combination of a firm strategy, that appears to have been set in Compass, should now be underpinned by a strong culture that encourages innovation.

\section{References}

Argyris, C. 1991. 'Teaching smart people how to learn', Harvard Business Review, May-June: 99-109.

Ashkanasy, N., Broadfoot, L.E. \& Falkus, S. 2000. 'Questionnaire measures of organizational culture'. In Ashkanasy, N., Wilderom, C. \& Peterson, M. (Eds.). Handbook of organizational climate and culture. Thousand Oaks: Sage Publications, pp. 131-45.

Beer, M. \& Eisenstat, R.A. 2000. 'The silent killers of strategy implementation and learning', Sloan Management Review, 41(4):29-40.

Beer, M. \& Nohria, N. 2000. 'Cracking the code of change', Harvard Business Review, May-June:133-41.

Blanchard, K. \& O'Connor, M. 1997. Managing by values. San Francisco: Berrett-Koehler.

Boon, M. 1997. The African way: The power of interactive leadership. $2^{\text {nd }}$ Edition. Sandton: Zebra Press.

Brown, A. 1995. Organisational culture. London: Pitman.

Compass, South Africa. 2001. Internal company document.

Christie, P., Lessem, R. \& Mbigi, L. 1993. (Eds.). African management: Philosophies, concepts and applications. Randburg: Knowledge Resources.

Connors, R. \& Smith, T. 2000. 'Benchmarking cultural transition', Journal of Business Strategy, 21(3):10-12.

Cummings, T.G. \& Worley, C.G. 2001. Essentials of organization development and change. Cincinnati: SouthWestern.

Deal, E.T. \& Kennedy, A.A. 1999. The new corporate cultures. Cambridge, Massachusetts: Perseus.

Garvin, D.A. 1993. 'Building a learning organisation', Harvard Business Review, July-August: 55-67.

Handy, C. 1985. Gods of management. London: Souvenir Press. 
Harrison, R. \& Stokes, H. 1992. Diagnosing organizational culture. San Diego: Pfeiffer.

Hatch, M.J. 1997. Organization theory: Modern symbolic and postmodern perspectives. New York: Oxford University Press.

Hofstede, G. 1997. Culture and organizations: Software of the mind. New York: McGraw Hill.

Jacques, E. 1952. The changing culture of a factory. New York : Dryden Press.

Jenks, C. 1993. Culture. London : Routledge.

Kotter, J.P. 1995. 'Leading change: Why transformation efforts fail', Harvard Business Review, March-April: 59-67.

Kotter, J.P. \& Heskett, J.L. 1992. Corporate culture and performance. New York: Free Press.

Markides, C. 1999. 'A dynamic view of strategy', Sloan Management Review, Spring: 55-63.

Nadler, D.A. \& Tushman, T.L. 1990. 'Beyond the charismatic Leader: leadership and organisational change', California Management Review, 32: 77-90.

Ogbonna, E. \& Harris, C. 2000. 'Leadership style, organizational culture and performance: Empirical evidence from UK companies', International Journal of Human Resource Management, 11(4): 766-88.

Ohmae, K. 1989. 'Planting for a global harvest: To grow a global company, first analyse the local environment', Harvard Business Review, July - August: 136 - 61.

Pettigrew, A. 1979. 'On studying organizational culture', Administrative Science Quarterly, 24: 570-81.

Robbins, S.P. 1998. Organizational behaviour. New Jersey: Prentice Hall.

Rokeach, M. J. 1973. The nature of human values. New York: The Free Press.

Schaefer, E. 2001. 'KKS champions change', Vision Magazine, February: 4.

Schein, E.H. 1992. Organizational culture \& leadership. San Francisco: Jossey-Bass.

Schein, E. H. 1996. 'Three cultures of management: The key to organisational learning', Sloan Management Review, September: 9-21.

Schwab, J.K. 1999. 'Introduction'. In Ashby, F.C. (Ed.). Your corporate culture: Powerful ways to transform your company into a high-performance organization. Houston: Cashman Dudley.

Senge, P.M. 1990. 'The leader's new work: Building learning organizations', Sloan Management Review, 32: 7-
23.

Siehl, C. \& Martin, J. 1984. 'The role of symbolic management: How can managers effectively transmit organizational culture?' In Hunt, J.D., Hosking, D., Schriesheim, C. \& Steward, R. (Eds.). Leadership and managers: International perspectives on managerial behavior and leadership. New York: Pergamon.

Struwig, F. \& Smith, E. 2002. 'The relationship between organisational culture and strategy formulation in South African firms', South African Journal of Business Management, 33(1):21-30.

Thomas, A. \& Bendixen, M. 2000. 'The management implications of ethnicity in South Africa', Journal of International Business Studies, 31(3):507-20.

Thomas, A. \& Turpin, M. 2002. 'Management values at the Southern Sun Group', South African Journal of Business Management, 33(2): 21-9.

Trompenaars, F. 1993. Riding the waves of culture: understanding cultural diversity in business. London: Nicholas Briely Publishing.

Ulrich, L. \& Lake, D. 1991. 'Organisational capability: creating competitive advantage', Academy of Management Executive, 5: 77-92.

Van der Post, W., De Coning, T. \& Smit, E. 1998. 'The relationship between organisational culture and financial performance: Some South African evidence', South African Journal of Business Management, 29(1): 30-40.

Welch, J. 2000. In 'GE's two-decade transformation: Jack Welch's leadership'. Harvard Business School Case Study (4). Case study no. 9-399-150. Boston: Harvard Business School Press.

Young, D.W. 2000. 'The six levers for managing organisational culture', Business Horizons, SeptemberOctober: 19-28. 